\title{
ONE YEAR OF DAILY SATELLITE ORBIT AND POLAR MOTION ESTIMATION FOR NEAR REAL TIME CRUSTAL DEFORMATION MONITORING
}

\author{
Yehuda Bock, Jie Zhang, Peng Fang, Joachim Genrich, Keith Stark \\ and Shimon Wdowinski
}

(IGPP A-025, Scripps Institution of Oceanography, 9500 Gilman Drive, University of California, San Diego, La Jolla, CA 92093, USA)

\begin{abstract}
The Permanent GPS Geodetic Array (PGGA) in southern California consists of five continuously operating stations established to monitor crustal deformation in near real time. The near real time requirement has been problematic since GPS satellite ephemerides and predicted earth orientation values (IERS Bulletins A and B) have been found to be neither sufficiently timely nor accurate to achieve horizontal position accuracies of several $\mathrm{mm}$ on regional scales. Therefore, we have been estimating precise GPS ephemerides and polar motion since August 1991. An examination of overlapping 24-hour satellite arcs indicates worst-case orbital errors of approximately 0.2 meters in the radial components, 1 meter in the cross-track components and 2-3 meters in the along-track components. A comparison with very long baseline interferometry indicates an accuracy of less than 1 mas in our determination of 24-hour values of pole position. These products are sufficiently timely and accurate to achieve several mm long-term horizontal precision in regional scale measurements of crustal deformation in near real time, as has been demonstrated during the 28 June, 1992 Landers and Big Bear earthquakes in southern California. The PGGA stations were able to detect seismically induced, sub-centimeter-level motions with respect to a terrestrial reference frame defined by the global tracking stations.
\end{abstract}

\section{INTRODUCTION}

The Permanent GPS Geodetic Array (PGGA) [Bock and Shimada, 1990; Lindqwister et al., 1991; Bock, 1991], established in southern California in the spring of 1990, is a network of five continuously operating GPS receivers (Fig. 1) providing an uninterrupted record of crustal motion in near real time. At each site there is a precise P-code GPS receiver with its antenna mounted on a stable geodetic monument. We have developed an automated system to collect, analyze and archive data from the PGGA sites. We monitor data at a 30 second sampling rate to all visible satellites, 24 hours a day, 7 days a week. Once a day the previous 24 hours of data are automatically collected from each site; standard GPS processing then provides the site position averaged over the day $\left(0-24^{\mathrm{h}}\right.$ UTC). The time series of these daily positions provides the standard record of crustal deformation.

To reduce orbital errors in our station position estimates, we estimate an ephemeris for each GPS satellite, using data collected by a globally distributed network of about 25 permanent tracking stations (Fig. 1). The global tracking network is usually described by the acronyms CIGNET and FLINN for Cooperative International GPS Network and Fiducial Laboratories for an International Natural science Network [Minster et al., 1992], and more recently by the International GPS Service (IGS) [Beutler, 1992]. In addition, to achieve near real time solutions, we compute corrections to tabulated predictions of the orientation of the earth's rotation axis (polar motion) which, if unaccounted for, could bias California station positions by several centimeters. The worldwide tracking network defines a global reference frame in which coordinates for the PGGA stations, in 
tectonically active southern California, can be computed with respect to rigid plate interiors (e.g., the North American plate).

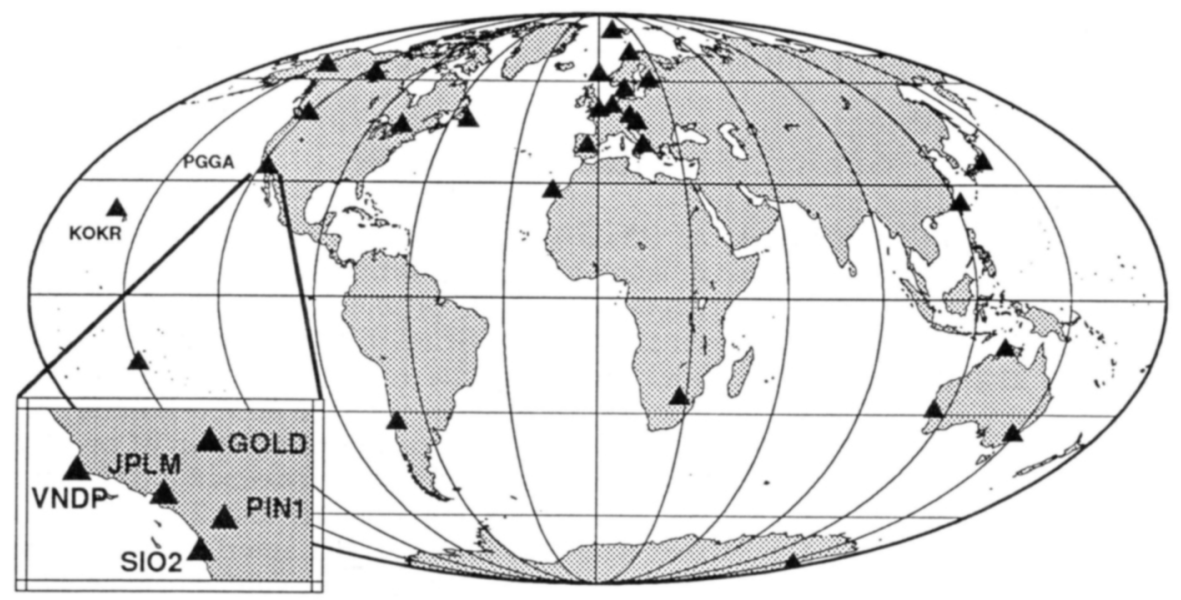

Figure 1: PGGA and global tracking stations used in the Scripps analysis

\section{ANALYSIS}

The PGGA and global tracking data are analyzed simultaneously and independently in twenty-four hour $\left(0-24^{\mathrm{h}}\right.$ UTC) segments using the GAMIT GPS software [King and Bock, 1992]. The observables used in a weighted least squares adjustment are doublydifferenced, dual-frequency phase measurements. The parameters estimated include station positions, single-day orbital arcs described by 6 initial conditions (position and velocity) and three solar radiation pressure parameters per satellite, one-per-day-perstation zenith tropospheric parameters, and phase ambiguity parameters for each independent (but arbitrary) double-difference combination. All parameters are given very loose constraints in the GAMIT adjustment and the variance-covariance matrix for the station and orbital parameters is stored in an auxiliary file. The auxiliary files are then input to the GLOBK software which uses a Kalman filter formulation [Herring et al., 1991] to estimate a consistent set of station positions and velocities, twenty-four hour orbital arcs and twenty-four hour polar motion values. The station positions and velocities (the reference frame) are estimated by forward filtering the twenty-four hour GAMIT-generated variance-covariance matrices; back filtering then produces the corresponding orbital arcs and polar motion. No estimate is made of UT1-AT since these deviations are absorbed into the orbital parameters.

To assess the precision of the twenty-four hour orbital arcs we compare 12 hour overlap periods between adjacent days. An examination of overlapping 24-hour satellite arcs indicates orbital errors of approximately 0.2 meters in the radial components, 1 meter in the cross-track components and 2-3 meters in the along-track components. Fig. 2 shows along-track overlaps for 5 Block I (PRN 6 went out of operation during this period) and 1 Block II (PRN 2) GPS satellites for the 14-month period between August 15, 1991 to October 21, 1992. 
Satellite PRN 2

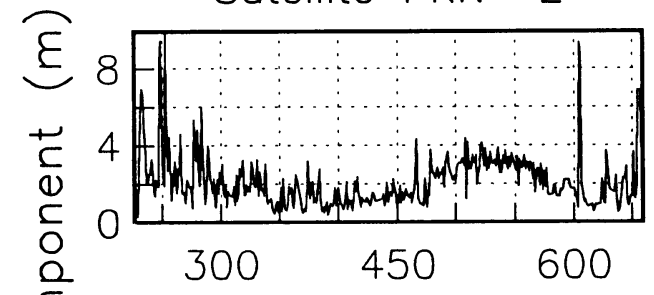

ह

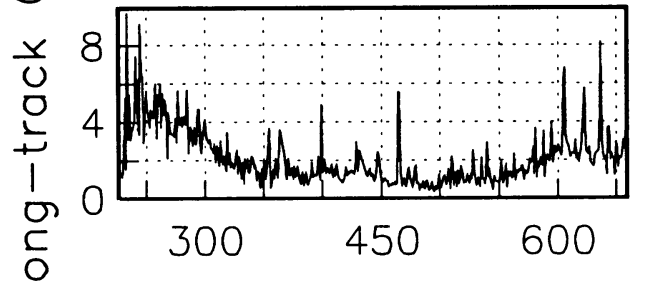

Satellite PRN 6

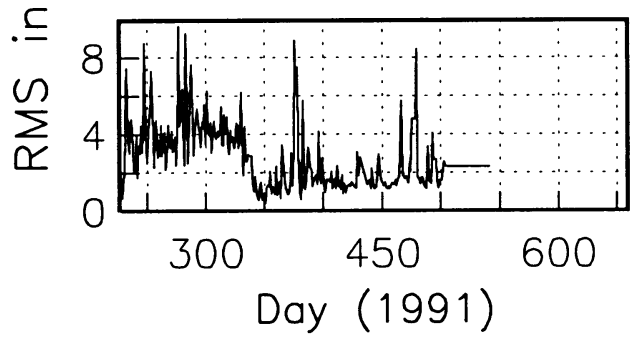

Satellite PRN 11

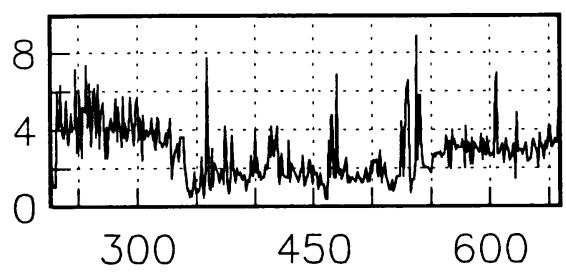

Satellite PRN 12

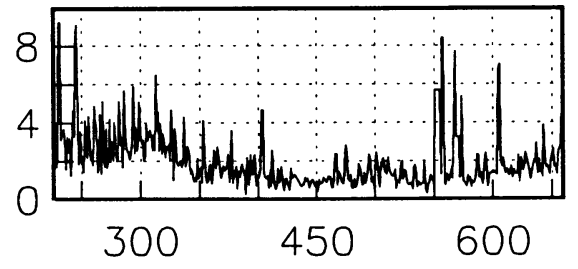

Satellite PRN 13

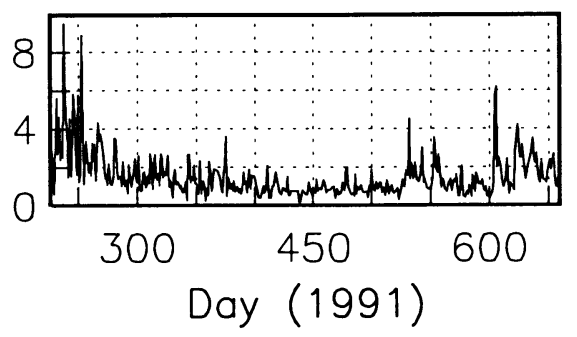

Figure 2: Along track overlaps for adjacent 24 hours orbital arcs. Each arc is extrapolated by 12 hours, the corresponding elements are differenced, and an rms deviation is computed.

The spikes for PRN 2 during the summer of 1992 correspond to weekends when antispoofing (AS) was turned on. Note that the overlap precision improves in time which corresponds to the growth of the global tracking network from about 12 stations in August 1991 to 25 stations by the start of the IGS campaign in June 1992. We know that the orbital precision indicated by the overlap comparison is pessimistic compared to the actual precision of baselines within PGGA with typical lengths of $100-150 \mathrm{~km}$. The overlap criterion indicates the precision of orbits extrapolated for a 12 hour period; the orbital elements within each 24 hour arc should be more precise. Note also that the overlap precision is computed for each satellite while baseline estimates are generated from doubly differencing phase measurements between all visible satellites. Nevertheless, it provides a useful lower-bound statistic for assessing the relative quality of the orbital arcs and for pointing out satellites with anomalous behavior.

Our uninterrupted daily determination of pole position is plotted in Fig. 3 for the period 14 August, 1991 to 12 November, 1992. In Fig. 4, we plot the difference between our pole positions and IERS Bulletin A. Our polar motion estimates have been compared with VLBI determined pole positions and indicate an accuracy of less than 1 mas in both components [T.A. Herring, D. McCarthy, M. Feissel, personal communication]. 


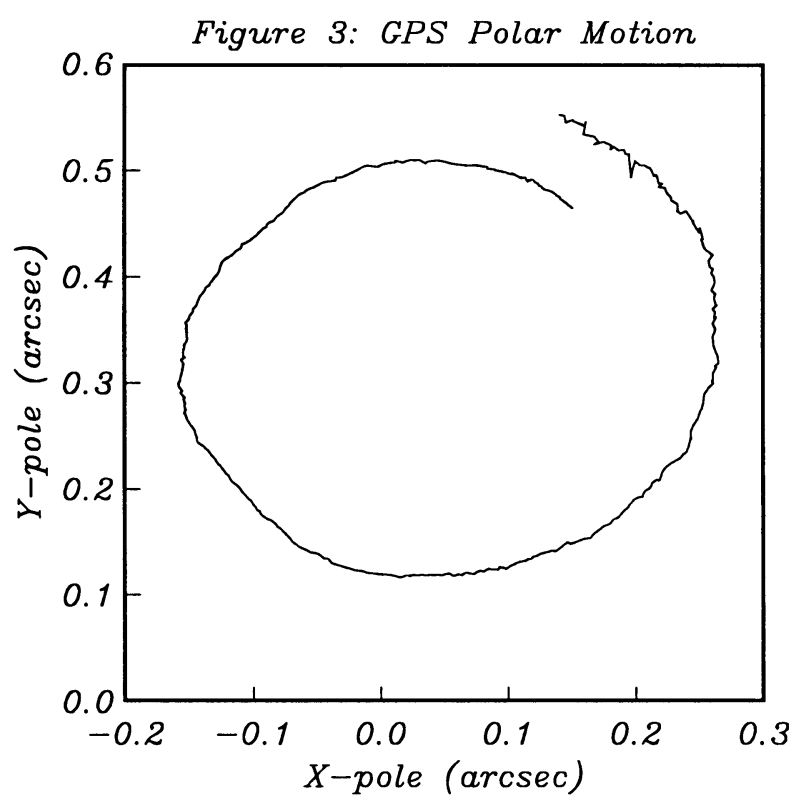

Figure 4: Comparison between GPS and IERS Bulletin A (1992)
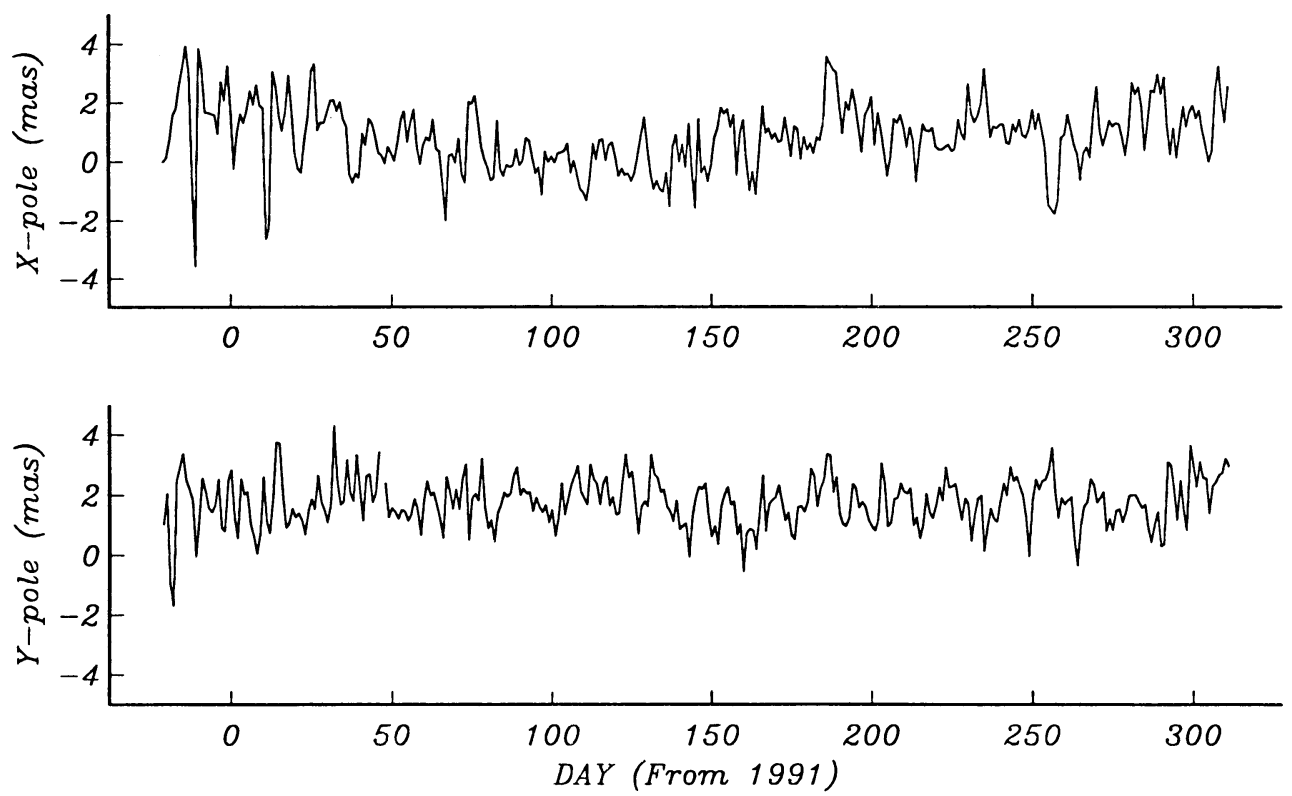


\section{DETECTION OF COSEISMIC DEFORMATION}

The Landers earthquake $\left(\mathrm{M}_{\mathrm{W}} 7.3\right.$, June $\left.28,1992,1158 \mathrm{UTC}, 34.20^{\circ} \mathrm{N}, 116.44^{\circ} \mathrm{W}\right)$, which was closely followed by the Big Bear earthquake $\left(\mathrm{M}_{\mathrm{W}} 6.21507\right.$ UTC), generated surface slip of up to 6 meters [Landers Earthquake Response Team, 1992; Kanamori et al., 1992]; the associated elastic deformation affected all the PGGA sites. The PGGA sites detected far-field coseismic horizontal displacements ranging between 4 to $46 \mathrm{~mm}$ which were determined by analyzing the daily 24-hour PGGA solutions over a 10 week period centered on the day of the earthquakes [Bock et al., 1992]. The PGGA sites were parameterized by two sets of coordinates: pre- and post-earthquake. For the day of the earthquakes, we computed the station positions separately from the 12 hours of data directly before the Landers earthquake and from the 9 hours of data after the Big Bear earthquake. The coseismic displacement of each PGGA site was determined by the variation in the positions before and after the earthquakes with respect to the global terrestrial reference frame defined by the positions and velocities of the global tracking stations (Fig. 1).

The site with the largest coseismic displacement $(46 \mathrm{~mm})$ is located at the Piñon Flat Observatory (PIN1), about $80 \mathrm{~km}$ from the seismic rupture zone. The horizontal coseismic displacement detected at PIN1 with respect to the global reference frame is shown in Figure 5 relative to the tracking station at Kokee Park (KOKR), Hawaii, more than $4000 \mathrm{~km}$ away The coseismic displacement appears clearly as a step function in the time series of daily station positions. An independent analysis of the PGGA and global tracking data by a group at the Jet Propulsion Laboratory yielded very similar coseismic displacements [Blewitt et al., 1992].

KOKR to PIN1

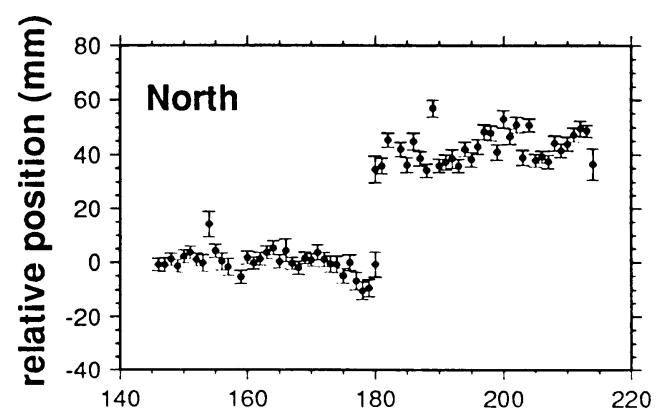

(Length $4,320.253 \mathrm{~km}$ )

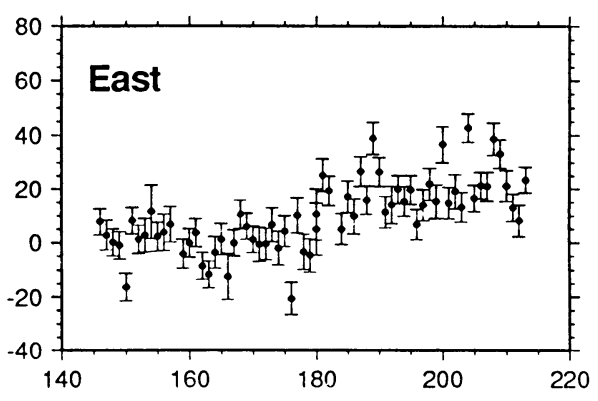

\section{day number, 1992}

Figure 5: Horizontal coseismic displacement observed at Piñon Flat Observatory with respect to the global reference frame, shown with respect to the station at Kokee Park, Hawaii. 


\section{CONCLUSIONS}

We have developed an operational system to produce orbital and earth orientation products for near real time monitoring of crustal deformation in southern California. The use of these products in monitoring the 28 June, 1992 Landers and Big Bear earthquakes by the PGGA indicates that we are able to detect sub-centimeter geophysical signals with respect to a terrestrial reference frame defined by the coordinates and velocities of a network of global tracking stations.

Acknowledgements. We thank our colleagues at the Jet Propulsion Laboratory, especially Steve Dinardo, for their role in maintaining the quality of the PGGA and much of the global tracking network, the U.S. National Geodetic Survey and Energy, Mines and Resources Canada, and all of the participants in the International GPS campaign (IGS) for their contribution of data and resources. We appreciate the assistance of Bob King and Tom Herring. We would also like our colleagues from the Shanghai Observatory for their hospitality. This work is supported by the National Aeronautics and Space Administration (NAGW-2641 and NAG 5-1917), the National Science Foundation (EAR 92 08447), the Southern California Earthquake Center USGS cooperative agreement (1408-00001-A0899) and the U.S. Geological Survey (1434-92-G2196). Y.B.'s work was performed in part through a Scripps/JPL joint appointment.

\section{REFERENCES}

Beutler, G. (1992), The 1992 activities of the International GPS Geodynamics Service, Eos, Trans. Amer. Geophys. Union, 73, 134.

Blewitt, G. et al., Absolute far-field displacements from the June 28, 1992, Landers earthquake sequence, submitted to Nature, 1992.

Bock, Y., and Shimada, S. (1990), Continuously monitoring GPS networks for deformation measurements, Global Positioning System: An Overview, Bock, Y. \& Leppard N., ed., Springer Verlag, New York, 40-56.

Bock, Y. (1990), Continuous monitoring of crustal deformation,GPS World, Aster Publishing Corporation, Eugene, Oregon, 40-47, June Issue.

Bock. Y., Agnew, D.C., Fang, P., J.F. Genrich, B.H. Hager, T.A. Herring, K.W. Hudnut, R.W. King, S. Larsen, J-B. Minster, K. Stark, S. Wdowinski and Wyatt, F.K., Detection of crustal deformation from the Landers earthquake sequence using continuous geodetic measurements, submitted to Nature, 1992.

Herring, T.H., Davis J.L. and Shapiro I.I. (199()), Geodesy by radio interferometry: The application of Kalman Filtering to the analysis of very long baseline interferometry data J. Geophys. Res. 95, 12,561-12,583.

International Earth Rotation Service, Bulletins B 51-54, Observatoire de Paris (1992), Bulletins A Vol. V, U.S. Naval Observatory (1992).

Kanamori, H., Thio, H.-K., Dreger, D., Hauksson, E. and Heaton, T., Initial investigation of the Landers, California, earthquakeof 28 June 1992, using TERRAscope, Geophys. Res. Lett., in press (1992).

King R.W. and Bock, Y. (1992), Documentation of the GAMIT GPS Analysis Software, Mass. Inst. of Technology and Scripps Inst. of Oceanography.

Landers Earthquake Response Team, Near-field investigations of the Landers earthquake sequence, April-July, 1992, submitted to Science (1992).

Lindqwister, U., Blewitt G., Zumberge J. and Webb F. (1991), Millimeter-level baseline precision results from the California permanent GPS Geodetic Array, Geophys. Res. Lett. 18, 1135-1138.

Minster, J-B., Hager, B.H., Prescott, W.H. and Schutz, R.E. (1991), International Global Network of Fiducial Stations, National Res. Council, National Academy Press, Washington, D.C.. 